\title{
BMJ Open Mental health in women 20-23 years after IVF treatment: a Swedish cross-sectional study
}

\author{
J Vikström, ${ }^{1,2}$ A Josefsson, ${ }^{1}$ M Bladh, ${ }^{1,2}$ G Sydsjö ${ }^{1,2}$
}

To cite: Vikström J, Josefsson A, Bladh M, et al. Mental health in women 20 23 years after IVF treatment: a Swedish cross-sectional study. BMJ Open 2015;5: e009426. doi:10.1136/ bmjopen-2015-009426

- Prepublication history for this paper is available online. To view these files please visit the journal online (http://dx.doi.org/10.1136/ bmjopen-2015-009426)

Received 20 July 2015 Revised 15 September 2015 Accepted 6 October 2015

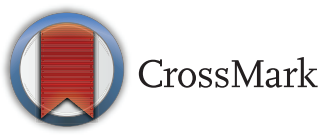

${ }^{1}$ Faculty of Health Sciences, Division of Obstetrics and Gynecology, Department of Clinical and Experimental Medicine, Linköping University, Linköping, Sweden

${ }^{2}$ Department of Obstetrics and Gynecology in Linköping, County Council of

Östergötland, Linköping,

Sweden

Correspondence to

J Vikström;

Josefin.vikstrom@liu.se

\section{ABSTRACT}

Objective: To assess self-perceived mental health in women treated with in vitro fertilisation (IVF) 20-23 years previously, while comparing them to a reference group, and to determine any differences in mental health between those who had given birth, those who had adopted a child, those who had given birth and adopted a child and those who remained childless.

Design: A cross-sectional study.

Setting: A Center of Reproductive Medicine (RMC) at a Swedish University hospital.

Participants: 520 women who had undergone at least one IVF cycle at the University Hospital in Linköping between 1986 and 1989. 504 of 520 women (97\%) were eligible for follow-up. While 34 women declined, 93 per cent $(n=470)$ of the women agreed to participate. The reference group consisted of 150 women of the Swedish population included in a study that was used to validate the Symptom CheckList (SCL)-90.

Interventions: Follow-up was conducted in 20082009. The SCL-90 was used to measure the women's self-perceived mental health and a questionnaire specific for this study was used to retain demographic information.

Outcome measures: The SCL-90 assesses 9 primary dimensions; somatisation, obsessive-compulsive, interpersonal sensitivity, depression, anxiety, hostility, phobic anxiety, paranoid ideation and psychoticism. There is also a global index of distress.

Results: Women who had previously undergone IVF treatment were at increased risk of symptoms of depression ( $p=0.017)$, obsessive-compulsion ( $p=0.02)$ and somatisation $(p \leq 0.001)$ when compared to a reference group. In addition, the women who have remained childless are at increased risk of symptoms of depression $(p=0.009)$ and phobic anxiety $(p=0.017)$.

Conclusions: The majority of the women who have been treated with IVF 20-23 years previously appear to be in good mental health. However, women who remain childless and/or without partner after unsuccessful infertility treatment constitute a vulnerable group even later on in life.

\section{INTRODUCTION}

Infertility, as well as its investigations and treatment, can cause psychological distress, ${ }^{1}$

\section{Strengths and limitations of this study}

- This is one of the few studies on the long-term mental health of women who have been treated with in vitro fertilisation.

- The follow-up period is exceptionally long at 20 23 years.

- The participation rate was very high at $93 \%$ $(n=470)$. Unfortunately, possible confounding factors such as educational level and life events could not be controlled for.

such as symptoms of anxiety and depression. $^{2-4}$ The infertility treatment itself further adds to the strain created by the infertility. ${ }^{5} 6$ In addition, childbirth is a known trigger for first-time episodes of psychiatric illness. ${ }^{7} 8$ However, Ross et al found in their review that there were no significant differences in the risk of experiencing symptoms of depression between those who had conceived spontaneously and those who had been treated with in vitro fertilisation (IVF).

Studies using self-reported symptoms as outcome measures when examining psychological well-being up to 10 years after IVF treatment have found that women who remain childless are at increased risk of anxiety, ${ }^{610}$ depression $^{610}{ }^{11}$ and stress ${ }^{11}$ and have a lower sense of coherence, ${ }^{10}$ selfesteem $^{11}$ and satisfaction with life ${ }^{11} 12$ than those who had given birth after treatment. Women who give birth as a result of treatment show a more positive long-term emotional status. ${ }^{4}$ Register-based studies using psychiatric diagnoses as outcome measures when examining risk of psychiatric illness after IVF treatment have varied in their results. Agerbo et $a l^{13}$ found that there were no differences between those who had given birth or remained childless after treatment in regard to risk of psychiatric illness but that the risk was lower among those who had adopted children. Another Danish registerbased study by Baldur-Felskov et $a l^{14}$ found 
that women who go through unsuccessful IVF treatment were at increased risk of hospitalisation due to most psychiatric disorders but that the risk of affective disorders were lower than for those who had given birth as a result of treatment. Meanwhile, Yli-Kuha et $a l^{15}$ showed that the risk of depression was increased in those who had gone through an unsuccessful treatment.

In regard to long-term effects of infertility and its treatment, Gameiro et $a l^{16}$ showed that women who had undergone infertility treatment 11-17 years previously suffered more mental health problems, when compared to the general population, and that a sustained child's wish negatively affected mental health. Meanwhile, studies have shown that most women come to terms with their parenthood goals. ${ }^{16-18}$ This shows that reorientation and coping after unsuccessful IVF treatment is important ${ }^{4}{ }^{19-21}$ and that couples may be in need of counselling after unsuccessful IVF treatment to resolve the grieving process. ${ }^{22}$ Twenty years after infertility treatment, the relationship quality in the couples who have previously undergone infertility treatment is good, ${ }^{23}$ although a qualitative study on 14 women showed that they still suffered negative effects of the infertility which were especially great when the women were going through the grandparent phase. ${ }^{24}$ Most studies have shown that childlessness does not influence psychological well-being in elderly individuals. ${ }^{25-28}$ Thus, there are only a few studies on the mental health of women who have been treated with IVF from a long-term perspective. It is still unclear what effects infertility and its treatment has on women in a long-term perspective.

The aim of the present study was to assess selfperceived mental health in a group of women treated with IVF 20-23 years earlier. Second, we wanted to study possible differences in mental health between the four groups: those who had given birth, those who had adopted a child, those who had given birth and adopted a child and those who remained childless.

\section{METHOD}

Subjects

All women $(n=520)$ who had received at least one IVF treatment cycle at the Center of Reproductive Medicine, University Hospital in Linkoping between 1986 and 1989 were, in 2008 to 2009, sent an introductory letter asking them to participate in the study. Six of the women were deceased and 10 women never received the letter; thus, 504 of $520(97 \%)$ women were eligible for follow-up. Of these, 10 women returned the letter declining participation and 24 women did not answer. Thus, a total of 470 of $504(93 \%)$ women eligible for follow-up agreed to participate. Of the $93 \%(n=470)$ of the women who agreed to participate, $55.1 \% \quad(\mathrm{n}=259)$ had biological children, $19.4 \%$ ( $\mathrm{n}=91)$ had adoptive children, 5.3\% $(\mathrm{n}=25)$ had both biological and adoptive children and $20.2 \%(\mathrm{n}=95)$ had remained childless. As a reference group, we used score mean values for 150 women of the general Swedish population. These data were derived from a population-based study, through which the Symptom CheckList (SCL)-90 was validated, of women older than 40 years of age. ${ }^{29} 30$

\section{Treatment procedures 1986-1989}

The couples were given three or more publicly funded IVF treatments during this time period. Some of the couples might have had at least one child before entering treatment during this period. The upper age limit for the women was 38 years at the time of treatment. The waiting time from acceptance to treatment was approximately 3 years.

\section{Outcome measures}

The SCL-90 was used to measure the women's selfperceived mental health during the past week. The SCL-90 is an extensively used multidimensional psychological status symptom inventory consisting of 90 items. ${ }^{29}{ }^{30}$ It is an objective method for symptom assessment requiring individuals to rate their psychopathological problems and symptoms. These symptoms are then used to compute scores for depression and anxiety. The scale is a five-point Likert scale ranging from 'not at all' (0) to 'extremely' (4). The SCL-90 assesses 9 primary dimensions: somatisation, obsessive-compulsive, interpersonal sensitivity, depression, anxiety, hostility, phobic anxiety, paranoid ideation and psychoticism. The cut-off score for each primary dimension was set at the 95th centile of self-reported symptoms in the study population in order to indicate a severe level of symptoms. ${ }^{31}{ }^{32}$ Hence, $>95$ th centile indicated 'Yes', meaning the occurrence of clinically relevant symptoms, and $\leq 95$ th centile indicated 'No'. There is also a global index of distress that can be used as a summary dimension. The cut-off score on the SCL-90 of $<70$ was used as an indicator of mental health. ${ }^{29}$

\section{Demographics}

Age, employment status, marital status, same/different partner since time of IVF treatment, number of children (biological and adopted), number of miscarriages and number of IVF treatments were assessed through a questionnaire specific for this study. Those with the same/ different partner since time of IVF treatment thus constitute a subgroup to those who were married/cohabiting.

\section{Statistics}

Two-sided $\chi^{2}$ tests were used to analyse differences between the subgroups in regard to background variables and self-perceived mental health. Student $t$ test, also two sided, was used to compare mean scores between all women who had received IVF treatment and those in the reference group. Effect sizes, using Cohen's distance, were calculated in order to evaluate the magnitude of the differences of the mean scores between IVF-treated women and women in the reference group. p Values $<0.05$ were considered significant. All statistical 
analyses were performed using IBM SPSS V.19 (IBM Corporation, Armonk, New York, USA).

\section{RESULTS}

\section{Demographics}

The distribution of demographics across the three groups is shown in table 1 . The majority of the women were older than 45 years at the time of follow-up. Those who had remained childless and those who had adopted children were significantly $(\mathrm{p} \leq 0.001)$ more likely to be aged over 45 years than were those with biological children. While $41.5 \% \quad(n=39)$ of the women without children were divorced or separated, the corresponding number for the women with biological children was $7.0 \%(\mathrm{n}=18)(\mathrm{p} \leq 0.001)$. Among those with adopted children, all women were married or cohabiting. Also, those with adopted children were the most likely to still be living with the same partner as they were at the time of IVF treatment (98.9\%; $\mathrm{n}=90)$. Those without children $(90 \% ; n=54)$ who were cohabiting or married were more likely than those with biological children $(70.6 \%$; $\mathrm{n}=175)$ to have remained with the same partner $(\mathrm{p} \leq 0.001)($ table 1$)$.

The women had, on average, been through 2.7 (range=1-10) IVF cycles and 189 of the women had experienced $1-10$ miscarriages (mean $=1.9$ ).

\section{Self-perceived mental health}

The women's own perceived mental health is displayed in table 2. Women who had biological or adoptive children were less likely to experience symptoms of phobic anxiety than women who had remained childless $(\mathrm{p}=0.017)$ (table 2). Also, women who had biological children were also significantly less likely than women who had remained childless to experience symptoms of depression $(p=0.009)$. Women who were separated, lived alone or were unemployed showed more signs of depression, anxiety and obsessive-compulsive problems compared to women who were married and were gainfully employed. Women who were over 45 years of age also had more symptoms of mental illness. Women who had changed partner since the time of IVF had more obsessive-compulsive symptoms compared to women who still had the same partner, but there were no other differences between these two groups (table 2).

In regard to 'Global severity index' and 'Positive symptom total', the women who had experienced infertility within the couple and who had been through a number of IVF treatments 20-23 years earlier showed the same pattern as the reference group (table 3). Only on the 'Positive symptom distress index' did the IVF group have a higher score indicating that these women had reported experiencing more intense symptoms. In regard to the specific symptoms, the women who had previously undergone IVF treatment were at increased risk of depressive and obsessive-compulsive symptoms as well as having increased scores for somatisation (table 3 ).

\section{DISCUSSION}

Principal findings

The majority of the women who had been treated with IVF 20-23 years previously reported few mental health

Table 1 Demographic data for the women treated with in vitro fertilisation $>20$ years ago $(n=470)$

\begin{tabular}{|c|c|c|c|c|c|c|c|c|c|c|c|}
\hline & \multicolumn{2}{|c|}{ Total } & \multicolumn{2}{|c|}{ No children } & \multicolumn{2}{|c|}{$\begin{array}{l}\text { Biological } \\
\text { children }\end{array}$} & \multicolumn{2}{|c|}{$\begin{array}{l}\text { Adoptive } \\
\text { children }\end{array}$} & \multicolumn{2}{|c|}{$\begin{array}{l}\text { Biological } \\
\text { and adoptive } \\
\text { children }\end{array}$} & \multirow[b]{2}{*}{ p Value } \\
\hline & $\mathbf{n}$ & Per cent & $\mathbf{n}$ & Per cent & $\mathbf{n}$ & Per cent & $\mathbf{n}$ & Per cent & $\mathbf{n}$ & Per cent & \\
\hline \multicolumn{12}{|l|}{ Employment status } \\
\hline Employed & 349 & 74.3 & 66 & 78.6 & 189 & 78.8 & 75 & 87.2 & 19 & 79.2 & 0.369 \\
\hline Missing & 36 & 7.7 & - & - & - & - & - & - & - & - & \\
\hline \multicolumn{12}{|l|}{ Marital status } \\
\hline Married/cohabiting & 411 & 87.4 & 55 & 58.5 & 240 & 93.0 & 91 & 100.0 & 25 & 100.0 & $<0.001$ \\
\hline Separated/divorced/other & 57 & 12.1 & 39 & 41.5 & 18 & 7.0 & 0 & 0.0 & 0 & 0.0 & \\
\hline Missing & 2 & 0.4 & - & - & - & - & - & - & - & - & \\
\hline \multicolumn{12}{|l|}{ Same partner } \\
\hline Yes & 343 & 73.0 & 54 & 90.0 & 175 & 70.6 & 90 & 98.9 & 24 & 96.0 & $<0.001$ \\
\hline Missing & 46 & 9.8 & & & & & & & & & \\
\hline \multicolumn{12}{|l|}{ Children } \\
\hline No children & 95 & 20.2 & - & - & - & - & - & - & - & - & - \\
\hline Biological children & 259 & 55.1 & - & - & - & - & - & - & - & - & \\
\hline Adoptive children & 91 & 19.4 & - & - & - & - & - & - & - & - & \\
\hline $\begin{array}{l}\text { Biological and adoptive } \\
\text { children }\end{array}$ & 25 & 5.3 & - & - & - & - & - & - & - & - & \\
\hline \multicolumn{12}{|l|}{ Age at follow-up } \\
\hline$\geq 45$ years old & 289 & 61.5 & 75 & 78.9 & 136 & 52.5 & 63 & 69.2 & 15 & 60.0 & $<0.001$ \\
\hline
\end{tabular}


Table 2 The study group women's self-perceived mental health assessed by the Symptom CheckList 90

\begin{tabular}{|c|c|c|c|c|c|c|c|c|c|c|c|c|c|c|c|c|c|}
\hline \multirow[b]{2}{*}{ Sociodemographic factors in $\%^{*}$} & \multicolumn{4}{|c|}{ Somatisation } & \multicolumn{3}{|c|}{$\begin{array}{l}\text { Interpersonal } \\
\text { sensitivity }\end{array}$} & \multicolumn{3}{|c|}{ Depression } & \multicolumn{3}{|c|}{ Anxiety } & & \multicolumn{3}{|c|}{ Hostility } \\
\hline & $\overline{\text { No }}$ & Yes & & p Value & No & Yes & p Value & No & Yes & p Value & No & Yes & p Value & & No & Yes & p Value \\
\hline \multicolumn{18}{|l|}{ Employment } \\
\hline Employed & 80.4 & 80.0 & \multicolumn{2}{|c|}{0.962} & 81.2 & 69.0 & 0.108 & 81.8 & 65.8 & 0.017 & 81.8 & 59.3 & 0.004 & \multicolumn{3}{|c|}{80.5} & 0.860 \\
\hline \multicolumn{18}{|l|}{ Marital status } \\
\hline Married/cohabiting & 88.4 & 76.2 & \multirow{2}{*}{\multicolumn{2}{|c|}{0.095}} & 88.4 & 80.0 & 0.176 & 88.8 & 76.9 & 0.030 & 88.6 & 75.9 & \multirow{2}{*}{\multicolumn{2}{|c|}{0.042}} & \multirow{2}{*}{$\begin{array}{l}88.1 \\
11.9\end{array}$} & 80.0 & \multirow[t]{2}{*}{0.347} \\
\hline Separated/divorced/other & 11.6 & 23.8 & & & 11.6 & 20.0 & & 11.2 & 23.1 & & 11.4 & 24.1 & & & & 20.0 & \\
\hline \multicolumn{18}{|l|}{ Age at follow-up } \\
\hline$\geq 45$ years old & 60.7 & 77.3 & \multicolumn{2}{|c|}{0.119} & 61.5 & 61.3 & 0.981 & 60.0 & 77.5 & 0.030 & 60.7 & 73.3 & 0.168 & & 61.7 & 56.3 & 0.661 \\
\hline \multicolumn{18}{|l|}{ Same partner } \\
\hline Yes & 81.1 & 75.0 & \multicolumn{2}{|c|}{0.541} & 81.5 & 70.8 & 0.197 & 81.2 & 77.4 & 0.609 & 81.3 & 73.9 & \multicolumn{2}{|l|}{0.381} & 81.3 & 66.7 & 0.203 \\
\hline \multicolumn{18}{|l|}{ Children } \\
\hline No children & 19.9 & 27.3 & & 0.159 & 19.4 & 32.3 & 0.188 & 18.4 & 40.0 & 0.009 & 19.5 & 30.0 & 0.420 & & 20.0 & 25.0 & 0.961 \\
\hline Biological children & 56.0 & 36.4 & & & 56.0 & 41.9 & & 56.7 & 37.5 & & 55.9 & 43.3 & & & 55.3 & 50.0 & \\
\hline Adoptive children & 19.2 & 22.7 & & & 19.6 & 16.1 & & 19.3 & 20.0 & & 19.1 & 23.3 & & & 19.4 & 18.8 & \\
\hline Biological and adoptive children & 4.9 & 13.6 & & & 5.0 & 9.7 & & 5.6 & 2.5 & & 5.5 & 3.3 & & & 5.3 & 6.3 & \\
\hline & Phok & ic an & ixiety & & & Paran & oid ideati & & & Psychoti & cism & & & Obse & essive & e-comp & sive \\
\hline Sociodemograpic factors in \%* & No & & Yes & & Value & No & Yes & $\mathbf{p ~ V z}$ & lue & $\overline{\text { No }}$ & Yes & p Value & & No & & Yes & p Value \\
\hline Employment & & & & & & & & & & & & & & & & & \\
\hline Employed & 81.9 & & 57.7 & & 0.003 & 81.3 & 65.2 & 0.05 & & 80.4 & 80.0 & 0.962 & & 81.6 & & 63.0 & 0.018 \\
\hline Marital status & & & & & & & & & & & & & & & & & \\
\hline Married/cohabiting & 88.4 & & 77.8 & & .100 & 87.8 & 87.5 & 0.96 & & 88.4 & 76.2 & 0.095 & & 88.6 & & 75.9 & 0.042 \\
\hline Separated/divorced/other & 11.9 & & 22.2 & & & 12.2 & 12.5 & & & 11.6 & 23.8 & & & 11.4 & & 24.1 & \\
\hline Age at follow-up & & & & & & & & & & & & & & & & & \\
\hline$\geq 45$ years old & 60.2 & & 82.1 & & 0.021 & 61.9 & 54.2 & 0.44 & & 60.7 & 77.3 & 0.119 & & 60.7 & & 77.3 & 0.119 \\
\hline Same partner & & & & & & & & & & & & & & & & & \\
\hline Yes & 80.6 & & 85.7 & & 0.973 & 82.1 & 57.1 & 0.09 & & 81.1 & 75.0 & 0.541 & & 82.3 & & 56.5 & 0.002 \\
\hline Children & & & & & & & & & & & & & & & & & \\
\hline No children & 18.8 & & 42.9 & & 0.017 & 20.4 & 16.7 & 0.69 & & 19.9 & 27.3 & 0.159 & & 19.1 & & 36.7 & 0.099 \\
\hline Biological children & 56.1 & & 39.3 & & & 54.7 & 62.5 & & & 56.0 & 36.4 & & & 55.7 & & 46.7 & \\
\hline Adoptive children & 19.9 & & 10.7 & & & 19.7 & 12.5 & & & 19.2 & 22.7 & & & 20.0 & & 10.0 & \\
\hline Biological and adoptive children & 5.2 & & 7.1 & & & 5.2 & 8.3 & & & 4.9 & 13.6 & & & 5.2 & & 6.7 & \\
\hline
\end{tabular}

$\mathrm{p}$ Values derived from Pearson $\chi^{2}$ statistic with significance level $<0.05$

Cut-off for each primary dimension: Yes $>95$ th centile (severe level of symptoms); No $\leq 95$ th centile.

*Percentage of individuals exhibiting the demographic factor for each category (Yes/No). 
Table 3 The study group of 470 women compared to the reference group of 156 age-matched women

\begin{tabular}{|c|c|c|c|c|c|c|c|}
\hline & \multirow[b]{2}{*}{ Cronbach's $\alpha$} & \multicolumn{2}{|c|}{$\begin{array}{l}\text { IVF women } \\
n=463-470\end{array}$} & \multicolumn{2}{|c|}{$\begin{array}{l}\text { Reference group } \\
\text { age-matched sample } \\
n=156\end{array}$} & \multirow{2}{*}{$\begin{array}{l}\text { Effect size } \\
\text { Cohen's } \\
\text { distance }\end{array}$} & \multirow[b]{2}{*}{ p Value } \\
\hline & & Mean & SD & Mean & SD & & \\
\hline Somatisation & 0.856 & 0.62 & 0.72 & 0.43 & 0.44 & $0.32^{*}$ & $<0.001$ \\
\hline Obsessive-compulsive & 0.864 & 0.57 & 0.68 & 0.49 & 0.52 & 0.13 & 0.020 \\
\hline Interpersonal sensitivity & 0.884 & 0.41 & 0.68 & 0.42 & 0.47 & 0.02 & 0.763 \\
\hline Depression & 0.921 & 0.62 & 0.80 & 0.52 & 0.58 & 0.14 & 0.017 \\
\hline Anxiety & 0.870 & 0.49 & 0.70 & 0.43 & 0.48 & 0.10 & 0.079 \\
\hline Hostility & 0.778 & 0.32 & 0.57 & 0.29 & 0.41 & 0.06 & 0.285 \\
\hline Phobic anxiety & 0.746 & 0.13 & 0.41 & 0.11 & 0.26 & 0.06 & 0.303 \\
\hline Paranoid ideation & 0.746 & 0.30 & 0.57 & 0.27 & 0.39 & 0.06 & 0.278 \\
\hline Psychoticism & 0.762 & 0.15 & 0.41 & 0.14 & 0.24 & 0.03 & 0.599 \\
\hline Global Severity Index & 0.975 & 0.41 & 0.60 & 0.38 & 0.38 & 0.06 & 0.291 \\
\hline Positive Symptom Distress Index & - & 3.84 & 6.15 & 1.40 & 0.43 & $0.56+$ & $<0.001$ \\
\hline Positive symptom total & - & 25.63 & 18.63 & 24.58 & 16.86 & 0.06 & 0.296 \\
\hline
\end{tabular}

problems. However, women who had remained childless 20 years after infertility treatment reported negative psychological consequences to a greater degree than those who had since become mothers. Childless women reported more symptoms of depression than did those with biological children and symptoms of phobic anxiety than did the women who had biological or adopted children. Women who had remained childless were to a greater degree separated or divorced, a group which to a greater degree reported suffering from depressive, anxiety and obsessive-compulsive symptoms. When all women who had undergone IVF treatment were compared to a reference group, we found that the IVF women reported more depressive, obsessive-compulsive and somatisation symptoms.

\section{Strengths and limitations}

The major limitation in this study is that we do not have data on mental health and life events at the start of IVF treatment or during the 20 years that have passed for the participating women. We can assume that most of the women have experienced their share of difficulties related to one or more of the major life events such as illness, job loss, death in the family and even trauma, but these are unfortunately not factors we could control for. However, it is reasonable to assume that the reference group would be equally affected by such factors. Unfortunately, we have no information on educational level of the participants which might have influenced the results. Also, no additional information, for example, parental status or fertility problems, was available for the reference group.

A great strength of this study is the high participation rate of $93 \%$. The reason for this surprisingly high rate might be that these women who were pioneers when
IVF treatment was started in Sweden have a strong desire to be involved in studies concerning questions on health, IVF and childlessness. Another strength is the long period of observation.

\section{Interpretation}

In accordance with previous studies, the results of this study indicate that infertility treatment, especially when unsuccessful, might increase the risk of a negative psychological symptomatology. ${ }^{10}{ }^{12}{ }^{24}$ Meanwhile, studies have shown that long-term psychological well-being is dependent on the ability to use coping skills ${ }^{14}{ }^{19-21}$ in order to overcome the grief process ${ }^{22}$ and also on whether or not the woman still sustains a wish for biological children. ${ }^{16}$ However, even if coping skills are successfully utilised, the grandparent phase, which the women of our study were just about to enter, might revoke the negative feelings that childlessness cause. ${ }^{24}$ While some previous studies have shown that the difference in psychological symptoms depend on whether there are any children in the family, biological or adoptive, ${ }^{12}$ others have shown only a positive influence of having biological children. ${ }^{14}$ Also, Munk-Olsen and coworkers $^{13}$ found that adoptive parents were at reduced risk of psychiatric illness. We found that some symptoms were decreased in both groups with children while the risk of depressive symptoms was only decreased in those with biological children.

Mental health is an important issue to study in the clinics where infertility investigations are conducted. The mental health and the lifestyle of women and men can be an indicator of, and explanation for, the fact that some women have trouble getting pregnant. For instance, anxiety disorders and depression might interfere with the couple's relationship and sexuality in a 
negative way, thus decreasing quality of life. It is often believed that emotional stress before trying to achieve pregnancy, naturally or through infertility treatment, will have a negative effect on pregnancy outcome. However, Boivin $e t a l^{33}$ showed, in a meta-analysis on 14 prospective studies, that pretreatment emotional distress did not negatively influence treatment outcome Owing to the limitations presented above, no firm conclusions regarding the long-term consequences of infertility treatment on mental well-being can be drawn. However, our results indicate that women who remain childless after IVF treatment might be at risk of experiencing negative psychological symptoms 20 years after treatment. In the future, we need to further explore the women who have a history of mental disorders or are vulnerable for mental ill-health in the IVF setting in order to not jeopardise their future mental health which could be negatively affected if the infertility treatment is unsuccessful. Also, for women who show signs of suffering from a mental disorder at the time of infertility investigation, counselling and treatment are important and medically correct actions need to be taken before starting infertility treatment. Moreover, women who remain childless after infertility treatment might be in need of follow-up and counselling to cope with their situation many years after infertility treatment.

\section{Conclusion}

In conclusion, the majority of the women who have been treated with IVF 20-23 years previously report few negative psychological symptoms. However, women who remain childless after unsuccessful infertility treatment constitute a vulnerable group that would most likely benefit from being observed in healthcare settings in order to prevent the evolvement of anxiety and depression symptoms and their side effects on somatic and psychological health.

Contributors JV participated in analysis, manuscript drafting and critical discussion and in the final preparation of the manuscript. AJ participated in analysis, manuscript drafting and critical discussion. MB participated in study design, execution and analysis. GS was involved in the research idea, design and execution, analysis, manuscript drafting and critical discussion. GS is the guarantor for the study.

Funding The study was supported by grants from The Health Research Council in the south east of Sweden.

\section{Competing interests None declared.}

Ethics approval The study has been approved by the Human Research Ethics Committee, in Linköping University (number 03-338, 9 September 2003).

Provenance and peer review Not commissioned; externally peer reviewed.

Data sharing statement The full data set and statistical code are available from the corresponding author at josefin.vikstrom@liu.se.

Open Access This is an Open Access article distributed in accordance with the Creative Commons Attribution Non Commercial (CC BY-NC 4.0) license, which permits others to distribute, remix, adapt, build upon this work noncommercially, and license their derivative works on different terms, provided the original work is properly cited and the use is non-commercial. See: http:// creativecommons.org/licenses/by-nc/4.0/

\section{REFERENCES}

1. Wichman C, Ehlers S, Wichman S, et al. Comparison of multiple psychological distress measures between men and women preparing for in vitro fertilization. Fertil Steril 2011;95:717-21.

2. Vahratian A, Smith YR, Dorman M, et al. Longitudinal depressive symptoms and state anxiety among women using assisted reproductive technology. Fertil Steril 2011;95:1192-4.

3. Volgsten H, Skoog Svanberg A, Ekselius L, et al. Prevalence of psychiatric disorders in infertile women and men undergoing in vitro fertilization treatment. Hum Reprod 2008;23:2056-63.

4. Verhaak CM, Smeenk JM, Nahuis MJ, et al. Long-term psychological adjustment to IVF/ICSI treatment in women. Hum Reprod 2007;22:305-8.

5. Greil A, McQuillan J, Lowry M, et al. Infertility treatment and fertility specific distress: a longitudinal analysis of a population-based sample of U.S. women. Soc Sci Med 2011;73:87-94.

6. Verhaak CM, Smeenk JMJ, Evers AWA, et al. Women's emotional adjustment to IVF: a systematic review of 25 years of research. Hum Reprod Update 2007;1327-36.

7. Munk-Olsen T, Agerbo E. Does childbirth cause psychiatric disorders? A population-based study paralleling a natural experiment. Epidemiology 2015;26:79-84.

8. Sejbaek CS, Pinborg A, Hageman I, et al. Are repeated assisted reproductive technology treatments and an unsuccessful outcome risk factors for unipolar depression in infertile women? Acta Obstet Gynecol Scand 2015;94:1048-55.

9. Ross LE, McQueen K, Vigod S, et al. Risk for postpartum depression associated with assisted reproductive technologies and multiple births: a systematic review. Hum Reprod Update 2011;17:96-106.

10. Johansson M, Adolfsson A, Berg M, et al. Gender perspective on quality of life, comparisons between groups 4-5.5 years after unsuccessful or successful IVF treatment. Acta Obstet Gynecol Scand 2010;89:683-91.

11. Bryson CA, Sykes DH, Traub Al. In vitro fertilization: a long-term follow-up after treatment failure. Hum Fertil 2000;3:214-20.

12. Hogström L, Johansson M, Jansson P-O. Quality of life after adopting compared with childbirth with or without assisted reproduction. Acta Obstet Gynaecolol Scand 2012;91:1077-85.

13. Agerbo E, Mortensen $P$, Munk-Olsen T. Childlessness, parental mortality and psychiatric illness: a natural experiment based on in vitro fertility treatment and adoption. J Epidemiol Community Health 2013;67:374-6.

14. Baldur-Felskov B, Kjaer SK, Albieri V, et al. Psychiatric disorders in women with fertility problems: results from a large Danish register-based cohort study. Hum Reprod 2013;28:683-90.

15. Yli-Kuha A-N, Gissler M, Klemetti R, et al. Psychiatric disorders leading to hospitalization before and after infertility treatments. Hum Reprod 2010;25:2018-23.

16. Gameiro S, van den Belt-Dusebout A, Bleiker E, et al. Do children make you happier? Sustained child-wish and mental health in women 11-17 years after fertility treatment. Hum Reprod 2014;29:2238-46.

17. Wischmann T, Korge K, Scherg H, et al. A 10-year follow-up study of psychosocial factors affecting couples after infertility treatment. Hum Reprod 2012;27:3226-32.

18. Sundby J, Schmidt L, Heldaas K, et al. Consequences of IVF among women: 10 years post-treatment. J Psychosom Obstet Gynaecol 2007;28:115-20.

19. Kraaij V, Garnefski N, Vlietstra A. Cognitive coping and depressive symptoms in definitive infertility: a prospective study. J Psychosom Obstet Gynaecol 2008;29:9-16.

20. Mindes EJ, Kathllen MI, Kliewer W, et al. Longitudinal analysis of the relationship between unsupportive social interactions and psychosocial adjustment among women with fertility problems. Soc Sci Med 2003:56:2165-80.

21. Peterson BD, Pirritano $\mathrm{M}$, Christensen $\mathrm{U}$, et al. The longitudinal impact of partner coping in couples following 5 years of unsuccessful fertility treatments. Hum Reprod 2009;24:1656-64.

22. Volgsten $H$, Skoog-Svanberg A, Olsson P. Unresolved grief in women and men in Sweden three years after undergoing unsuccessful in vitro fertilization treatment. Acta Obstet Gynecol Scand 2010;89:1290-7.

23. Sydsjö G, Skoog Svanberg A, Lampic C, et al. Relationship in IVF couples 20 years after treatment. Hum Reprod 2011;26: 1836-42.

24. Wirtberg I, Möller A, Hogström L, et al. Life 20 years after unsuccessful infertility treatment. Hum Reprod 2007;2:598-604.

25. Vikström J, Bladh M, Hammar M, et al. The influences of childlessness on the psychological well-being and social network of the oldest old. BMC Geriatr 2011;11:78. 
26. Zhang Z, Hayward M. Childlessness and the psychological well-being of older persons. J Gerontol B Psychol Sci Soc Sci 2001;56:S311-20.

27. Bures R, Koropeckyj-Cox T, Loree M. Childlessness, parenthood, and depressive symptoms among middle-aged and older adults. $J$ Fam Issues 2009;30:670-88.

28. Koropeckyj-Cox T, Pienta A, Brown T. Women of the 1950s and the "normative" life course: the implications of childlessness, fertility timing and marital status for psychological well-being in late midlife. Int J Aging Hum Dev 2007;64:299-330.

29. Derogatis LR. Manual 1 Scoring, administration and procedures for the SCL-90. Baltimore: Clinical Psychometric Research, 1977.
30. Fridell M, Cesarec Z, Johansson M, et al. SCL-90 Svensk normering, standardisering och validering av symptomskalan. Statens institutionsstyrelse (SiS), 2002/04.

31. van der Velden $\mathrm{P}$, Rademaker A, Vermetten $\mathrm{E}$, et al. Police officers: a high-risk group for the development of mental health disturbances? A cohort study. BMJ Open 2013;3:e001720.

32. Korenromp M, Page-Christiaens $\mathrm{G}$, van den Bout $\mathrm{J}$, et al. Adjustment to termination of pregnancy for fetal anomaly: a longitudinal study in women at 4, 8, and 16 months. Am J Obstet Gynecol 2009;201:160.e1-7.

33. Boivin J, Griffiths E, Venetis CA. Emotional distress in infertile women and failure of assisted reproductive technologies: meta-analysis of prospective psychosocial studies. BMJ 2011;23:342. 